\title{
Effects of Cement Bases on the Stresses and Deflections in Composite Restorations
}

\author{
J. W. FARAH, J. M. POWERS, J. B. DENNISON, R. G. CRAIG, \\ and $J$. SPENCER \\ School of Dentistry, University of Michigan, Ann Arbor, Michigan 48104, USA
}

\begin{abstract}
A model was used to show that tensile and shear stresses can occur in sufficient magnitude to cause failure in a cement base supporting a composite material in a posterior Class I restoration. Highest values of stress were observed when lining materials with a low modulus were used.
\end{abstract}

The principal use of composites is in Class III, IV, and V restorations in anterior teeth. A two-year clinical study by Phillips et all,2 indicated that composites may also be used in cavities in posterior teeth when appearance is important. For the same reason, they can be used in Class $\mathrm{I}$ and $\mathrm{V}$ cavities.

In a preliminary report, Vieira, Coradazzi, and Mondelli ${ }^{3}$ studied the rupture strength of composites in chromium-cobalt dies with Class II preparations. Their data were inconclusive and their choice of the model was not too realistic, since the modulus of elasticity of chromium-cobalt alloys is at least eight times that of dentin.

The model in this investigation has been successfully used (1) to investigate stresses and deflections in cavity floors under various loading conditions, ${ }^{4}$ and (2) to investigate the stresses induced in a Class I amalgam restoration supported by bases of varying materials and thickness. 5 The main advantage of this model is that it is capable of accounting for the mechanical properties of a natural tooth and of any restorative material functioning under Hook's law. In this study, the model has been slightly modified to study the stresses and deflections in a posterior Class I composite restoration supported by various cement bases. Although Class I com-

Received for publication October 22, 1974.

Accepted for publication July 28, 1975. posite restorations are not usually advocated clinically, the cavity design was used because it lends itself better to the available model. The behavior of the cement base in any other cavity design under identical loading conditions will be similar, and its interpretation is, therefore, applicable to other cavity designs.

\section{Materials and Methods}

A first molar was idealized by an axisymmetric model and analyzed as described in an earlier article by Farah, Hood, and Craig. $\bar{a}$ The morphology and composition of the model refiected the actual properties of dental tissues and are depicted in Figure 1. Various combinations of cement bases, cement-base thicknesses, and a composite restoration of constant dimensions were simulated in the cavity preparations and were subjected to a $45 \mathrm{~kg}$ instantaneous load to minimize the viscoelastic behavior of dentin. The Joad was axisymmetrically applied and annularly concentrated as shown in planar form in Figure 1.

The following cases were simulated and the modulus of elasticity and Poisson's ratio for the various portions of the model are listed in the table. In case $\mathrm{K}_{1}$, the base (Fig 1, line $\mathrm{C}-\mathrm{D}$ ) of the composite restorations was supported by $2 \mathrm{~mm}$ of zinc polyacrylate cement; in cases $K_{2}$ and $K_{3}$, the preparations were similar to those for $K_{1}$ except for an increase in the modulus of the composite as indicated in the table; in case $L$, the base of the composite restoration (line C-D) was supported by $2 \mathrm{~mm}$ of zinc phosphate cement; in case $M$, the base of the composite restoration (line $\mathrm{C}$-D) was supported by $1.5 \mathrm{~mm}$ of zinc phosphate over $0.5 \mathrm{~mm}$ of zinc oxide-eugenol (ZOE) liner; 


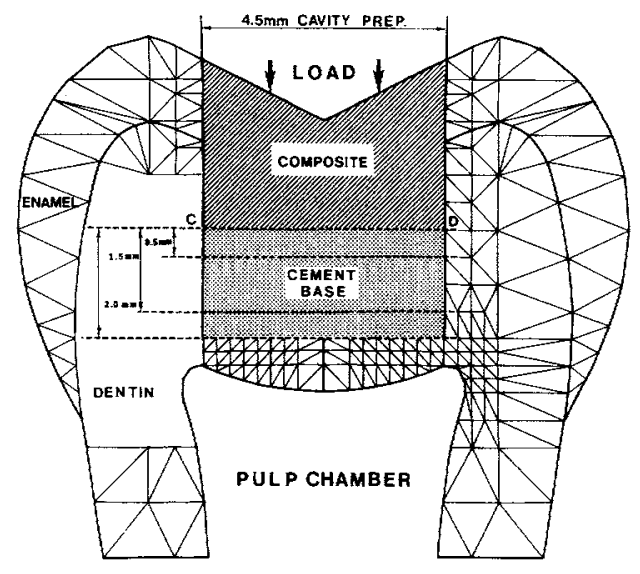

Fig 1.-Axisymmetric model for finite element analysis of composite restoration.

and in case $\mathrm{N}$, the base of the composite restoration (line C-D) was supported by 0.5 $\mathrm{mm}$ of calcium hydroxide liner, which in turn was supported by dentin.

The maximum shearing, compressive, and tensile stresses, as well as the deflections, just above the composite-base interface denoted by line $C-D$, and at various levels in the cement base were calculated as was explained earlier.5

\section{Results}

The cavity preparations, as well as the various cement-base thicknesses, are presented in Figure 1. In Figure 2, the maxi-

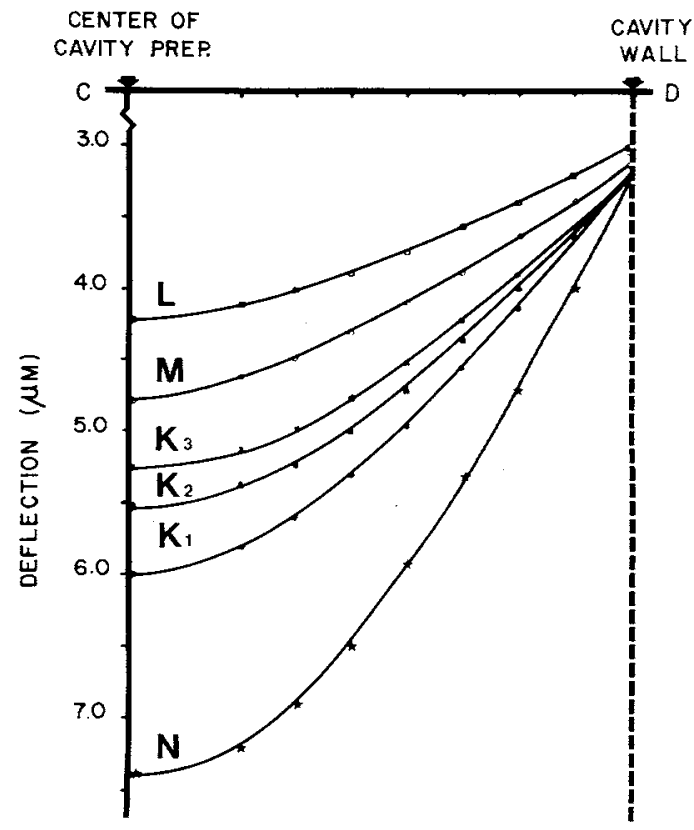

Fig 2.-Deflection along line C-D at compositebase interface. Case $K_{1}$ represents composite $\left(E=8,300 \mathrm{MN} /\right.$ meter $^{2}$ ) supported by $2 \mathrm{~mm}$ zinc polyacrylate. Case $\mathrm{K}_{2}$ represents composite $(E=$ $12,450 \mathrm{MN} /$ meter $^{2}$ ) supported by $2 \mathrm{~mm}$ zinc polyacrylate, Case $K_{3}$ represents composite $(E=$ 16,600 $\mathrm{MN} /$ meter $^{2}$ ) supported by $2 \mathrm{~mm}$ zinc polyacrylate. Cases $\mathbf{L}, \mathbf{M}$, and $\mathrm{N}$ represent composite $\left(E=8,300 \mathrm{MN} /\right.$ meter $\left.^{2}\right)$ supported by 2 $\mathrm{mm}$ zinc phosphate, $1.5 \mathrm{~mm}$ zinc phosphate over $0.5 \mathrm{~mm}$ zinc oxide-eugenol, and $0.5 \mathrm{~mm}$ calcium hydroxide, respectively.

TABLE

Modulus of Elasticity and Poisson's Ratio of Materials SIMULATED IN MODEl ${ }^{\text {a-B }}$

\begin{tabular}{|c|c|c|c|}
\hline Material & Cases & $\begin{array}{l}\text { Modulus of } \\
\text { Elasticity } \\
\text { (MN/meter }\end{array}$ & $\begin{array}{l}\text { Poisson's } \\
\text { Ratio }\end{array}$ \\
\hline Enamel & $\mathbf{K}_{1}-\mathbf{N}$ & 82,500 & 0.33 \\
\hline Dentin & $\mathbf{K}_{1}-\mathbf{N}$ & 18,600 & 0.31 \\
\hline \multirow{3}{*}{$\begin{array}{l}\text { Composite restora- } \\
\text { tive resin }\end{array}$} & $\mathbf{K}_{1}, \mathbf{L}, \mathbf{M}, \mathbf{N}$ & 8,300 & 0.28 \\
\hline & $\mathbf{K}_{\mathbf{2}}$ & 12,450 & 0.28 \\
\hline & $\mathbf{K}_{3}$ & 16,600 & 0.28 \\
\hline $\begin{array}{l}\text { Zinc polyacrylate } \\
\text { cement base }\end{array}$ & $\mathbf{K}_{1}, \mathbf{K}_{2}, \mathbf{K}_{3}$ & 4,950 & 0.25 \\
\hline $\begin{array}{l}\text { Zinc phosphate } \\
\text { cement base }\end{array}$ & $\mathbf{L}, \mathbf{M}$ & 22,400 & 0.35 \\
\hline ZOE cement liner & $\mathbf{M}$ & 288 & 0.40 \\
\hline $\begin{array}{l}\text { Calcium hy- } \\
\text { droxide liner }\end{array}$ & $\mathbf{N}$ & 367 & 0.40 \\
\hline
\end{tabular}




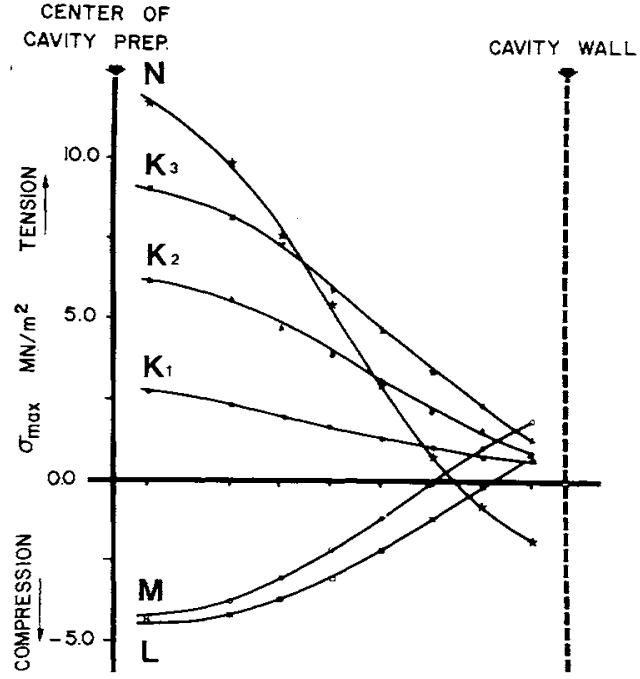

Fig 3.-Maximum stresses in composite restoration above line $C$-D supported by various cement bases. Case $K_{1}$ represents composite $(E=$ $8,300 \mathrm{MN} /$ meter $^{2}$ ) supported by $2 \mathrm{~mm}$ zinc polyacrylate. Case $\mathrm{K}_{2}$ represents composite $(E=$ $12,450 \mathrm{MN} /$ meter $^{2}$ ) supported by $2 \mathrm{~mm}$ zinc polyacrylate. Case $\mathrm{K}_{3}$ represents composite $(E=$ 16,600 $\mathrm{MN} /$ meter $^{2}$ ) supported by $2 \mathrm{~mm}$ zinc polyacrylate. Cases $\mathrm{L}, \mathrm{M}$, and $\mathrm{N}$ represent composite $\left(E=8,300 \mathrm{MN} /\right.$ meter $\left.^{2}\right)$ supported by 2 $\mathrm{mm}$ zinc phosphate, $1.5 \mathrm{~mm}$ zinc phosphate over $0.5 \mathrm{~mm}$ zinc oxide-eugenol, and $0.5 \mathrm{~mm}$ calcium hydroxide, respectively.

mum deflection along line $\mathrm{C}$-D was plotted to demonstrate the effects of the various bases on the deflection in the composite. A decided increase in the deflection is seen when the composite is supported by $0.5 \mathrm{~mm}$ of calcium hydroxide liner (case $\mathrm{N}$ ) as compared with support by $2 \mathrm{~mm}$ of zinc phosphate cement base (case L). It should be pointed out that the lines in Figures 2 to 5 were plotted from the center of the cavity to the cavity wall, thus taking advantage of the symmetry of the model. In Figure 3, the maximum stresses just above the compositebase interface are shown. Figure 4 depicts the maximum stresses $\left(\sigma_{\max }\right)$ that occur at any level in the cement bases supporting the composite restoration. Only small variations in $\sigma_{\max }$ occurred in the cement as the mod. ulus of the composite was increased from 8,300 to $16,600 \mathrm{MN} /$ meter $^{2}$ (cases $\mathrm{K}_{1}, \mathrm{~K}_{2}$. and $\left.\mathrm{K}_{\mathbf{3}}\right)$. High tensile stresses $\left(\sigma_{\max }=15.2\right.$ $\mathrm{MN} /$ meter $^{2}$, case $M$ ) were encountered in the zinc phosphate cement base when it was supported by $0.5 \mathrm{~mm}$ of ZOE cement liner.

The maximum shearing stresses in the cement bases are plotted in Figure 5. The shear stresses for cases $K_{1}$ through $K_{3}$ were similar; however, the shear stresses in cases $\mathrm{L}$ and $M$ increased by almost twofold when compared with stresses in cases $K_{1}$ through $\mathrm{K}_{\mathbf{3}}$.

\section{Discussion}

This study uses the induced stresses and deflections in the composite adjacent to the composite-base interface and the stresses in the cement bases supporting the composite as the index of the supporting ability of the base material, and therefore, its ability to prevent failure of the restoration. The pulpal floor of the cavity preparation was assumed to be placed on sound dentin, and it was further assumed that all dental tissues

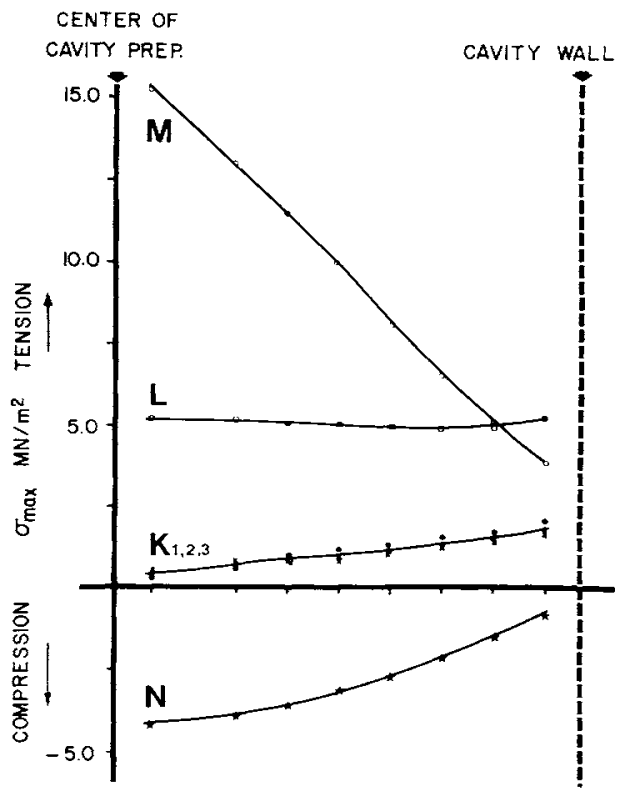

Fig 4.-Maximum stresses in various cement bases supporting composite restoration. Case $\mathrm{K}_{1}$ represents composite $\left(E=8,300 \mathrm{MN} /\right.$ meter $\left.^{2}\right)$ supported by $2 \mathrm{~mm}$ zinc polyacrylate. Case $\mathrm{K}_{2}$ represents composite $\left(E=12,450 \mathrm{MN} /\right.$ meter $^{2}$ ) supported by $2 \mathrm{~mm}$ zinc polyacrylate. Case $K_{3}$ represents composite $\left(E=16,600 \mathrm{MN} / \mathrm{meter}^{2}\right)$ supported by $2 \mathrm{~mm}$ zinc polyacrylate. Cases $\mathrm{L}$, $\mathrm{M}$, and $\mathrm{N}$ represent composite $(E=8,300 \mathrm{MN} /$ meter ${ }^{2}$ ) supported by $2 \mathrm{~mm}$ zinc phosphate, 1.5 mm zinc phosphate over $0.5 \mathrm{~mm}$ zinc oxideeugenol, and $0.5 \mathrm{~mm}$ calcium hydroxide, respectively. 


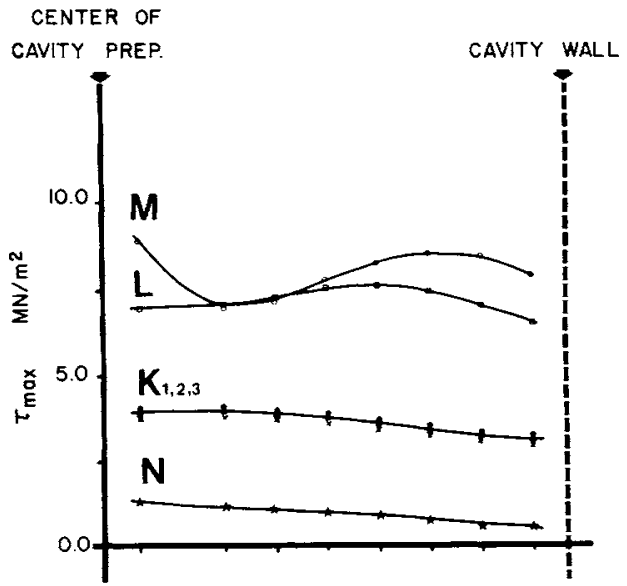

Fic 5.-Maximum shearing stresses in various cement bases supporting composite restoration. Case $K_{1}$ represents composite $(E=8,300 \mathrm{MN}$ ) meter $^{2}$ ) supported by $2 \mathrm{~mm}$ zinc polyacrylate. Case $K_{2}$ represents composite $(E=12,450 \mathrm{MN} /$ meter ${ }^{2}$ ) supported by $2 \mathrm{~mm}$ zinc polyacrylate. Case $\mathrm{K}_{3}$ represents composite $(E=16,600 \mathrm{MN}$ ) meter $^{2}$ ) supported by $2 \mathrm{~mm}$ zinc polyacrylate. Cases L, M, and $\mathrm{N}$ represent composite ( $E=$ $8,300 \mathrm{MN} /$ meter $^{2}$ ) supported by $2 \mathrm{~mm}$ zinc phosphate, $1.5 \mathrm{~mm}$ zinc phosphate over $0.5 \mathrm{~mm}$ zinc oxide-eugenol, and $0.5 \mathrm{~mm}$ calcium hydroxide, respectively.

as well as the restorative materials used functioned in a linear fashion (Hooke's law). The restorative material also was assumed to be fixed to the cavity wall, or, in other words, to have good retention to the dentin and enamel of the axial walls.

Examination of the deflection curve in Figure 2 shows the gradual decrease in the deflection at the composite-base interface as the modulus of the composite is increased from $8,300 \mathrm{MN} /$ meter $^{2}$ in case $\mathrm{K}_{1}$, to 12,450 $\mathrm{MN} /$ meter $^{2}$ in case $\mathrm{K}_{2}$, and finally to 16,600 $\mathrm{MN} /$ meter $^{2}$ in case $\mathrm{K}_{3}$. A more dramatic decrease in defiection might be expected as the modulus is doubled, but this is not so because the deflection is inversely proportional to the modulus and is given by $U=\frac{r}{E}$ $\left[\sigma_{\theta}-v\left(\sigma_{r}+\sigma_{z}\right)\right]$, where $U$ is the deflection; $r$, the radius; $E$, the modulus; $v$, Poisson's ratio; and $\sigma_{\theta}, \sigma_{r}$, and $\sigma_{z}$ are the stresses along the various axes. In cases $K_{1}$ through $K_{3}$, the composite was supported by a zinc polyacrylate base where the modulus was 4,950
$\mathrm{MN} /$ meter $^{2}$. As this base was replaced by one with a higher modulus, case $L$, the maximum deflection along line $\mathrm{C}$-D was reduced further. Alternatively, in case $\mathrm{N}$, a $0.5 \mathrm{~mm}$ thickness of a calcium hydroxide liner, with a modulus of only $367 \mathrm{MN} /$ meter $^{2}$, caused a large deflection in the composite. It can be concluded, therefore, that everything being equal the magnitude of the deflection in the composite is controlled by the modulus of the base. Obviously, Poisson's ratio (see case $\mathrm{K}_{1}$ ) also plays a role; however, the variations in Poisson's ratio for different elastic materials are usually of a small order.

In Figure 3 the $\sigma_{\max }$ stresses just above line C-D, most of which are tensile, are plotted to demonstrate the effects of the cement base on the tensile stresses in the composite restoration. The maximum tensile stresses in the composite restoration occurred in case $\mathrm{N}$ where the composite was supported by $0.5 \mathrm{~mm}$ of a calcium hydroxide liner. The maximum tensile stress was at the center of the cavity and was about $12 \mathrm{MN} /$ meter $^{2}$, which is well below the tensile strength of most composite restorative materials, whose strengths lie between 30 and $40 \mathrm{MN} /$ meter $^{2}$ (ref 6). This result indicates that the chances of fracture of a composite restoration at the composite-base interface are remote. However, the model treated here assumes the existence of very ideal conditions at and within the cavity preparation (that is, homogeneity of the restorative material, application and distribution of the load, complete retention at the cavity wall, and above all, the lack of clinically introduced variables). Any one of the foregoing could cause a decided increase in the maximum tensile stresses in the composite restoration. In areas close to the point of application of the load, the tensile and compressive stresses could exceed $55 \mathrm{MN}$ /

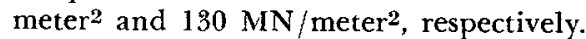

In Figures 4 and 5 , the maximum tensile and shear stresses in the various cement bases are shown. The tensile stresses in the cement were highest in case $M$ where a 1.5 mm layer of zinc phosphate cement base was supported by a $0.5-\mathrm{mm}$ layer of ZOE cement liner. The maximum tensile stress occurred at the center of the cavity preparation and in the layer of zinc phosphate immediately above the ZOE. Figure 4 shows that $\sigma_{\max }$ was greater than $15 \mathrm{MN} /$ meter $^{2}$ which is at least twice the value of the tensile strength 
found by Powers, Farah, and Craig ${ }^{8}$ for zinc phosphate cement with a base consistency. Furthermore, $\sigma_{\max }$ in case $M$ was at least three times the value of $\sigma_{\max }$ in case $L$, where a 2-mm layer of zinc phosphate was used. These results show the deleterious effect that layering of two cements with significantly different moduli can have on cement bases. The tensile stresses encountered in the cement base were more than sufficient to fracture the base and thus create high stress concentration areas in the restoration, which could lead to the fracture and failure of the restoration.

Two ways of overcoming the high tensile stresses caused by layering are: (1) to use only one cement base with a modulus of about $8,000 \mathrm{MN} /$ meter $^{2}$, that is, a base close to the modulus of the restorative material; or (2) to reduce as much as possible the thickness of the layer of cement with the low modulus. Figure 4 shows that the tensile stresses in the cement were not drastically affected by changing the modulus of the composite, cases $\mathrm{K}_{1}$ to $\mathrm{K}_{3}$. The tensile stresses of the zinc phosphate cement chosen for the model have adequate strength and distribute the stresses uniformly across its surface.

The $\sigma_{\max }$ stresses in the cement for case $\mathrm{N}$ were compressive in nature, which implies that the calcium hydroxide liner functions somewhat like a sponge because of the lack of sufficient strength in the cement itself. Such behavior is obviously not an advantage since it will induce higher deflection in the composite as demonstrated in Figure 2. Calcium hydroxide liners should, therefore, be used in very thin layers just sufficient to fulfill their purpose. Finally, the maximum shear stresses in the cements are plotted in Figure 5 and again the modulus of the composite had little effect on the shearing stresses in the cements (cases $K_{1}$ to $K_{3}$ ). In comparison with other cements, low-shearing stresses were encountered in case $\mathrm{N}$, but again the calcium hydroxide liner possesses very low-strength properties and should be used in thin layers and only in areas of very low stress. For any restorative material the tensile, compressive, and shear stresses should be considered in order to have a full understanding of the strength properties of the materials. Knowing the compressive strength of cements or of any restorative material is not sufficient for the selection of the proper material. The compressive stresses were not presented in detail in this study since in all cases the maximum compressive stresses encountered in the cements were lower than the compressive strength found by Powers, Farah, and Craig. 8 For example, in cases $K_{1}$ to $K_{3}$ the maximum compressive stresses did not exceed $10 \mathrm{MN} /$ meter $^{2}$, whereas the strength of a zinc polyacrylate base in compression is about $70 \mathrm{MN} /$ meter $^{2}$; in cases $\mathrm{L}$. and $M$ the maximum compressive stress of the zinc phosphate cement base did not exceed $15 \mathrm{MN} /$ meter $^{2}$, whereas its measured strength is about $150 \mathrm{MN} /$ meter $^{2}$. Only in cases $\mathrm{M}$ and $\mathrm{N}$ for the calcium hydroxide and ZOE liners did the computed value come close to the value quoted by Powers, Farah, and Craig, ${ }^{8}$ that is, the maximum compressive stress encountered in calcium hydroxide and ZOE liners in this study was 6.3 MN/ meter $^{2}$ and $1.4 \mathrm{MN} /$ meter $^{2}$ compared to the measured compressive strengths of $8.4 \mathrm{MN}$ / meter $^{2}$ and $5.5 \mathrm{MN} /$ meter $^{2}$, respectively.

\section{Conclusions}

A model was used to investigate stresses and deflections in cement bases and in a composite restorative material induced in a posterior Class I restoration. Deflections in the composite were highest when it was supported by a base with a low modulus; however, the maximum tensile stress (12 $\mathrm{MN} /$ meter $^{2}$ ) occurring in the composite restoration at the interface with the base was well below the maximum tensile strength of most composite materials (30 to $40 \mathrm{MN}$ / meter $\left.{ }^{2}\right)$. Tensile and shear stresses occurring in the cement base were of sufficient magnitude to exceed the strength of the cement when a $1.5-\mathrm{mm}$ layer of zinc phosphate cement (base consistency) was supported by a 0.5-mm layer of ZOE lining material. Lowest values of stress were observed when a $2-\mathrm{mm}$ layer of a zinc polyacrylate base was used to support the composite restoration. An ideal situation would be to have a cement base with a modulus of elasticity equal to that of the composite material. Finally, the maximum stress and deflection values obtained here can be easily exceeded in a clinical situation when wider variations can be easily introduced, making the choice of a cement with the proper modulus even more critical.

\section{References}

1. Phillips, R.W.; Avery, R.D.; Mehra, R.; SwarTz, M.L.; and McCune, R.J.: One-Year 
Observations on a Composite Resin for Class II Restorations, I Prosthet Dent 26: 68-77, 1971.

2. Phillips, R.W.; Avery, R.D.; Mehra, R.; SwartZ, M.L.; and MCCunE, R.J.: Observations on a Composite Resin for Class II Restorations: Two-Year Report, J Prosthet Dent 28: 164-169, 1972.

3. Vieira, D.F.; CoradazzI, L.J.; and Mondelli, J.: Comparative Study on the Strength of Restorative Materials in Class II Cavities, Estomatologia E Cultura 5:101-106, 1971.

4. Farah, J.W.; HoOd, J.A.A.; and CraIG, R.G.: Stress and Deflections in the Floor of Model Cavity Preparations, J Oral Rehabilitation I: 207-215, 1974.
5. Farah, J.W.; Hood, J.A.A.; and Craig, R.G.: Effects of Cement Bases on the Stress in Amalgam Restorations, J Dent Res 54: 10-15, 1975.

6. Dennison, J.B., and Craig, R.G.: Physical Properties and Finished Surface Texture of Composite Restorative Resins, JADA 85: 101108, 1972.

7. Halt, D.R.; Nakayama, W.T.; Grenoble, D.E.; and KATA, J.L.: Elastic Constants of Three Representative Dental Cements, $J$ Dent Res 52:390, 1973.

8. Powers, J.M.; Farah, J.W.; and Craig, R.G.: Modulus of Elasticity and Strength Properties of Dental Cements, $J A D A$, in press. 